\title{
Recent Developments in Alternatives to Animal Testing
}

\author{
Katy Taylor \\ Director of Science and Regulatory Affairs, Cruelty Free International \\ (formerly BUAV) and the European Coalition to End Animal Experiments, \\ London, United Kingdom
}

\section{Introduction to Alternative Methods}

At least 115 million animals are thought to be used for scientific purposes every year, worldwide (Taylor et al., 2008). Animals are typically used to test whether an intervention will cause harm to humans or other animals of the same or different species, i.e. safety testing; or whether it will work, i.e. efficacy testing. Interventions can include testing substances (such as cosmetic products, industrial chemicals, drugs, pesticides, food additives, and biocides); medical devices; surgical techniques; environmental changes; or other ways of altering the physiology and/or behavior of a live animal. Safety testing is highly regulated and is often done after any efficacy testing, if necessary, to finally check that an intervention is safe for humans and/or other animals to use. Efficacy testing is less formalized and often occurs in universities as ideas are tested in live animals as a "proof of concept", often prior to the development of actual interventions to help humans or other animals.

Methods that replace techniques that use live animals, or methods of testing substances without live animal use, are known as alternatives, replacements or non-animal methods. Some prefer the term advanced technologies given the fact that they often rely on more sophisticated technology and are more human-relevant than the animal test they replace (see Langley et al., 2015). There have been efforts to replace animal tests since the 196os. Significant progress initially came in replacing animals used to diagnose human disease; to produce biological drugs (such as vaccines); and to safety test batches of these drugs as they were produced. Concerns about safety were the initial driver for this, as drugs produced using animal material could be contaminated with animal diseases. However, cost, efficiency, and the need for swifter and more accurate predictions also played a part. Some of the earliest replacements are, in fact, no longer referred to as such, as they are now standard practice. For example, the

(C) KATY TAYLOR, 2019 | DOI:10.1163/9789004391192_025 
polio vaccine used to be produced in primary monkey kidney cells, resulting in the death of tens of thousands of monkeys every year. However, by the 1970s, the use of long-lived human or monkey cells in culture was common place and the risk of contamination with animal viruses was also eliminated (Bookchin and Schumacher, 2005). Batches of the vaccine against yellow fever used to be tested for efficacy (potency) on animals in lethal dose tests, but these tests were replaced by a cell culture test, the plaque-reduction neutralization test, in the 1970s (World Health Organization, wHO, 2007).

As analytical techniques improved, as well as scientific understanding, animals were no longer used as indicators of disease because disease-causing agents were now both understood and could be measured directly. For example, every batch of insulin used to be checked using 600 mice and tens of thousands were used in the United Kingdom alone every year. The mouse convulsion test was a particularly unpleasant test, as the number of mice that went into convulsions following injection was used as a measure of the strength of vials of insulin. Now, analytical methods can measure the components of insulin directly (Underhill et al., 1994). Similarly, rabbits were used in the diagnosis of pregnancy. A rabbit was injected with the urine from a potentially pregnant woman, and if the rabbit's ovaries swelled (detected upon killing and dissecting the rabbit), this was considered a good predictor of pregnancy (Friedman, 1939). Now, of course, we know that the substance indicative of pregnancy is gonadotrophin, which can be detected directly using chemical tests.

Nowadays, alternative methods can include a range of techniques, including cell-based tests (in vitro); tests using tissue taken from dead humans or animals (exvivo); chemical-based analytical tests (in chemico); computer-based modelling (in silico); and ethical human studies (in vivo). Using examples of these types of methods used for regulatory safety testing, this chapter illustrates the difficulties seen in replacing animals and how they can be overcome.

Recent Developments in Alternatives to Toxicity Testing

The past 30 years have seen a dramatic increase in the development of alternatives to animals (see Liebsch et al., 2011). Advances in replacements are more recognized in the field of toxicology because it is this area that has received the most attention. Regulatory, typically toxicity testing, is only a small proportion of the global testing on animals (8\% in Europe according to Daneshian et al., 2015); but due to the standardized nature of the tests, replacement of just one test has a permanent effect on the use of animals in that area and is, therefore, seen as particularly worthwhile. 
Table 24.1 outlines the status of alternatives for the most common tests used for chemical safety testing, which traditionally and in most cases still use animals. Two things stand out in this table. First, that replacement of topical endpoints (i.e., tests that measure effects on the external parts of the body) are almost completely replaced. However, alternative tests for systemic, broad effects, such as repeated dose, do not yet feature in the regulatory acceptance column. Second, there has been significant progress in the past 10 years in regulatory acceptance. Many tests have gained approval from the Organisation for Economic Co-operation and Development (OECD), even if they can only be used in combination with other tests.

TABLE 24.1 Alternatives for standard toxicity tests for chemical safety

\begin{tabular}{|c|c|c|c|}
\hline Endpoint & Animal test & Alternative tests & $\begin{array}{l}\text { Regulatory } \\
\text { acceptance }\end{array}$ \\
\hline $\begin{array}{l}\text { Skin } \\
\text { absorption }\end{array}$ & $\begin{array}{l}\text { The substance is rubbed } \\
\text { onto the shaved backs of } \\
\text { rats, and they are killed } \\
\text { the next day (OECD TG } \\
427 \text { ). }\end{array}$ & $\begin{array}{l}\text { Exvivo skin-based tests that } \\
\text { measure the amount of } \\
\text { substance that passes through } \\
\text { excised skin. }\end{array}$ & $\begin{array}{l}\text { OECD TG } 428 \\
(2004) . \text { Standalone } \\
\text { replacement. }\end{array}$ \\
\hline $\begin{array}{l}\text { Acute } \\
\text { toxicity }\end{array}$ & $\begin{array}{l}\text { Rats are exposed to a } \\
\text { very high dose of the } \\
\text { substance, such that } \\
\text { a number of them } \\
\text { are expected to die } \\
\text { (OECD TG 402,403, } \\
420,423,425,436) \text {. }\end{array}$ & $\begin{array}{l}\text { Cell-based tests, in particular } \\
\text { the } \mathrm{NRU}_{3} \mathrm{~T}_{3} \text {, which measures } \\
\text { the extent of cell death in the } \\
\text { presence of the substance. }\end{array}$ & $\begin{array}{l}\text { Not formally ac- } \\
\text { cepted, can be used } \\
\text { in combination with } \\
\text { other information } \\
\text { only. }\end{array}$ \\
\hline $\begin{array}{l}\text { Skin } \\
\text { irritation/ } \\
\text { corrosion }\end{array}$ & $\begin{array}{l}\text { Substance is rubbed onto } \\
\text { the shaved backs of rab- } \\
\text { bits, and they are killed } \\
2 \text { weeks later (OECD TG } \\
404 \text { ). }\end{array}$ & $\begin{array}{l}\text { Reconstituted in vitro human } \\
\text { skin models that measure } \\
\text { the extent of cell death in the } \\
\text { presence of the substance. }\end{array}$ & $\begin{array}{l}\text { OECD TG } 431(2004) \\
\text { and } 439(2010) \text {, plus } \\
\text { others. Testing strat- } \\
\text { egy accepted (OECD, } \\
\text { 2014a). }\end{array}$ \\
\hline $\begin{array}{l}\text { Eye } \\
\text { irritation/ } \\
\text { corrosion }\end{array}$ & $\begin{array}{l}\text { Substance is placed into } \\
\text { the eyes of live rabbits } \\
\text { who are monitored for } \\
\text { up to } 3 \text { weeks (OECD TG } \\
405 \text { ). }\end{array}$ & $\begin{array}{l}\text { Excised eyes from hens and } \\
\text { cattle killed for food (ex vivo) } \\
\text { can detect non-irritants and } \\
\text { severe irritants; human cor- } \\
\text { neal epithelial (HCE) models } \\
\text { based on excised human skin } \\
\text { or corneas that measure the }\end{array}$ & $\begin{array}{l}\text { OECD TG } 437 \text { and } \\
438 \text { (ex vivo, 20o9); } \\
\text { OECD TG } 492 \text { (HCE, } \\
\text { 2015). Testing strate- } \\
\text { gies yet to be formally } \\
\text { accepted. }\end{array}$ \\
\hline
\end{tabular}


TABLE 24.1 Alternatives for standard toxicity tests for chemical safety (cont.)

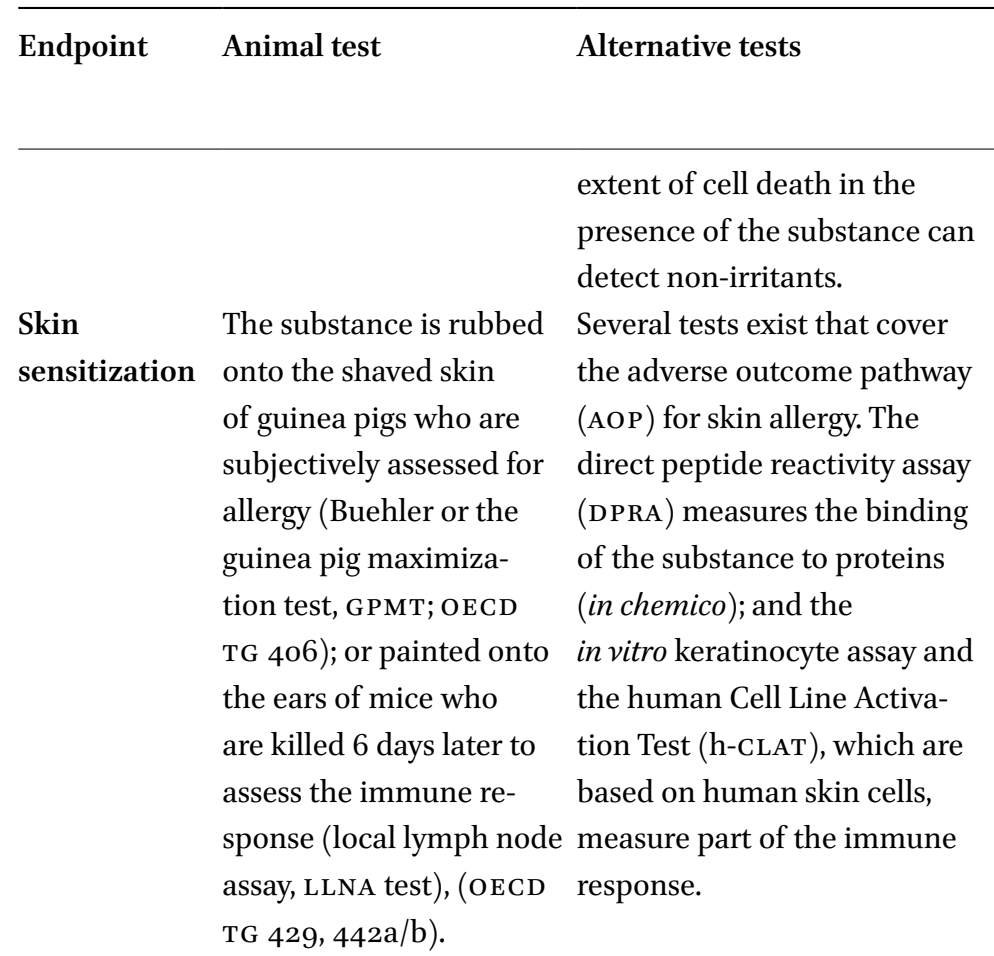

Muta- $\quad$ The substance is force- Several in vitro tests, including

Regulatory

acceptance

genicity/ fed or injected into mice bacteria (Ames) tests, in vitro

OECD TG 471 (1997);

genotoxicity or rats for 14 days; they

chromosome aberration, cell

473 (1997); 476

are then killed to look at micronucleus, and gene muta-

(1997); 487 (2010);

the effects on their cells

tion tests are available.

490 (2015). Positive

(OECD TG 474, 475, 483, A battery of two or three cellresults, however still $486,488,489$ ).

based tests is always carried

lead to follow up in

vivo.

out before conducting an

animal test.

\begin{tabular}{|c|c|c|c|}
\hline & $\begin{array}{l}\text { Rats (occasionally } \\
\text { rabbits, mice, or dogs) } \\
\text { are force-fed, forced to } \\
\text { inhale, or have the sub- } \\
\text { stance rubbed onto their } \\
\text { shaved skin every day } \\
\text { for } 28 \text { or } 90 \text { days, before } \\
\text { being killed (OECD TGs } \\
407-413) \text {. }\end{array}$ & $\begin{array}{l}\text { In silico techniques, such as } \\
\text { read across, can be used if the } \\
\text { substance is similar to existing } \\
\text { ones that have already been } \\
\text { tested. } \\
\text { A battery of in vitro tests or lab } \\
\text { on a chip models are still in } \\
\text { the development phase. }\end{array}$ & $\begin{array}{l}\text { Read across is ac- } \\
\text { cepted on a case-by- } \\
\text { case basis (see OECD, } \\
2014 \text { b); battery of } \\
\text { in vitro tests or lab } \\
\text { on a chip are not yet } \\
\text { accepted. }\end{array}$ \\
\hline
\end{tabular}


Carcinogenicity

Rats or mice are fed the substance for two years to see if they get cancer (OECD TG 451, 452).

Reproductive Pregnant female rabbits toxicity or rats are force-fed the
Cell transformation assays (CTA) based on cellular changes to rodent cells have been in use for 50 years and can detect $90 \%$ of known human carcinogens.

In silico techniques, such as read across, can be used if the substance and then killed along with their unborn babies (OECD TG 414). substance is similar to existing ones that have already been tested.The in vitro Embryonic Stem cell (EST) test is based on mouse stem cells. Substances are classed as toxic if they block development into beating heart cells.

Other in vitro tests are still in the development phase. Receptor binding assays are in vitro assays that can detect activation of genes involved in hormone production.
CTA assays have failed to gain international regulatory acceptance and are used for screening purposes only (OECD 2015, 2016).

Read across is accepted on a case-bycase basis (see OECD, 2014b). EST has failed to gain international regulatory acceptance. Receptor binding assays (OECD TG 455, 2012; 457, 2012; 456, 2011) are accepted to screen for potential endocrine disrupting properties.

For a list of all OECD Test Guidelines referred to in this table, see http://www.oecd.org/chemicalsafety/testing/oecdguidelinesforthetestingofchemicals.htm.

It is widely acknowledged that public pressure has played a significant part in encouraging these developments. Public outrage at animal testing for cosmetics started in the 1970s and gained momentum in the 1980s. In Europe, the outcry turned into calls for an actual ban on cosmetics testing on animals, even in the absence of alternatives for all relevant animal tests. From 1993, and finally ending in 2013, a series of deadlines were negotiated and re-negotiated within the European Union (EU) by which the testing had to end, first for the testing of products and then for the testing of ingredients (European Commission, 2017). During this period, the cosmetics industry foresaw that testing any new substances on animals would soon have to end, and they invested in alternatives, as did the European Commission (EC).

The formal encouragement to use alternatives in the EU was set in stone by the EU Directive on animal testing in 1986 (Council of the European 
Communities, 1986, Directive 1986/6og/EEC) and revised in 2010 (European Parliament, 2010, to Directive 2010/63/EU). Directive 2010/63/EU states that an animal test must not be conducted if an alternative method is available. This rule is unique to the EU; and while not enforced as well as one might hope, it has nonetheless helped encourage the promotion of alternatives internationally. Finally, the overhaul of EU chemicals' legislation in 2006 also played a part in driving the need for alternative methods. The new chemical regulation, Registration, Evaluation, Authorisation and Restriction of CHemicals $(\mathrm{REACH})$ is interesting in that it requires the testing of all new and existing chemicals on animals, unless alternative methods or data already exist (European Parliament and the Council of the European Union, 2006, Regulation 1907/2006). The fact that this could result in the use of up to 38 million animals (Joint Research Centre, 2006), has encouraged both regulators and industry to look for alternatives to keep costs and animal numbers down.

\section{Implementation of Alternative Methods}

The replacement of an animal test is a laborious and lengthy, scientific and bureaucratic process. Figure 24.1 outlines the steps that typically need to be taken before an animal test can be finally considered replaced by another method. Unfortunately, the outlined process is often repeated for each sector of use. For example, the method needs to be validated and accepted for replacing animals to test chemicals and then repeated in order for the method to be considered acceptable to replace animals used in drug testing. This is because the types of chemicals differ in each sector, and there is a fear that the alternative may not work on different chemistries. There is also an element of distrust in alternatives not developed for that sector, and so the industry tends to want to reevaluate the alternative itself rather than transfer it across immediately.

Development is the stage in which the alternative is created, optimized, and initially tested. Academe plays a large role at this stage. Alternative centers, such as the UK National Centre for the 3 Rs and alternatives charities, are vital in funding this kind of work. Researchers may develop spin-off companies to further develop a method. Larger chemical, medical, and cosmetics companies

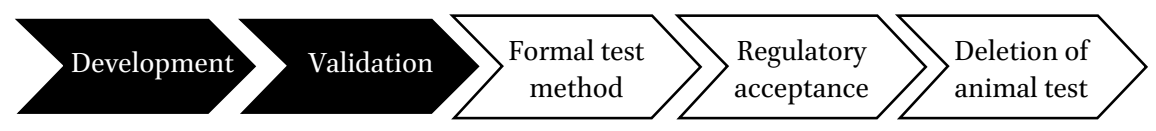

FIGURE 24.1 The process of acceptance of an alternative test method. Steps in black are primarily science driven, steps in white are primarily regulatory driven. 
may also develop alternatives, even creating their own spin-off companies or buying existing ones. For example, L'Oréal purchased the rights to EpiSkin in 1997 and bought the SkinEthic company in 2006, so that they could develop and use their own human skin irritation models (Auplat, 2012). Unfortunately, academics may be satisfied by the publication of their method in scientific journals and often leave it to others to ensure it is used more widely. More proactive, academic-driven development may still struggle to grasp the regulatory hurdles that need to be overcome before the method can be used. Unfortunately, industry-driven development can also be rather inward looking. Companies may be satisfied if the method is considered suitable for their own in-house purposes for screening substances; and, often, they have little incentive to donate the method to the wider community, particularly if they have invested heavily in its development, and competitors could gain from its use.

Validation is the stage in which the method is independently assessed to ensure it is reliable and accurate. This step is vital if the method is to progress to acceptance. There are internationally agreed principles for the way a method should be validated; but they are rather vague and not always well understood. The key requirements include, showing that the method produces the same results when tested at different times in the same laboratory and when used by other naive laboratories, and that the results are consistent with what is expected, i.e. the test does what it is designed to do. The process is laborious, requires collaboration between several laboratories, and can be expensive. If things go wrong, the validation stage may have to be repeated. In most cases, historical animal test data is used as the gold standard by which an alternative method is assessed, so no new animal tests have to be done; but there can be problems in ensuring the old animal data is of good quality. Quite often, the fact that the animal test itself was never validated causes problems during validation, as the assessors realize that the animal data is so unreliable or inaccurate that they cannot trust it (Balls, 2006). Species differences also play a significant role in making comparisons between human-based cell tests and animal test results very difficult (Hartung, 2007).

Official bodies are seen as a good way of ensuring a method is correctly validated. In Europe, the European Commission's European Centre for the Validation of Alternative Methods (ECVAM) is an important validation body. There are now equivalent bodies in other countries, such as the United States (US) (Interagency Coordinating Committee on the Validation of Alternative Methods, ICCVAM), and Japan (Japanese Centre for the Validation of Alternative Methods, JaCVAM). Unfortunately, the process of validation and regulatory acceptance is still a bit of a black box. Methods do not have to go through these validation centers to be accepted, but it often helps. Companies with 
new methods are often unsure about the process, whether they need to submit their method for official validation or directly to the regulatory body, who they should contact, and what information they need to provide.

Formal test method. Once there is sufficient evidence that an alternative method is valid, the next stage is to write up how the method should be performed as a formal test method. In Europe, the policy is to gain wider agreement on the method via large international collaborations, such as the OECD or the International Council on Harmonization (ICH). This is so that the method, in theory, will be accepted outside Europe and European companies will not be disadvantaged by having to conduct other tests. Negotiating how to conduct the method is often combined with further analysis of the validity of the method and can take several years. This stage can also provide false hope that a method is acceptable in all regions; this is because, although an agreement may be sought in principle, at an international level, the regional acceptance process can be prolonged as regulators still have to decide that the method is relevant and acceptable to the legal framework in their region.

Regulatory acceptance does not automatically happen following the publication of a formal test method, a fact that is often not widely appreciated. Following adoption of a formal test method, typically several regional regulatory agencies have to assess independently whether the method can be used for their sector (e.g., chemical, medicines, or cosmetics). Unfortunately, there is often no official mandate for them to do this, and they may need political pressure to act. Regulators do not have to wait until the method is formally recognized internationally to decide whether they will accept it for their purposes, but they frequently do. Negotiations within each regulatory body can take many months, or even years; and currently, these have to happen separately for each sector and region. Regulators typically accept methods by updating their guidelines, but it is often only when a corresponding legislation is changed that industry becomes aware of the need to use the alternative in place of the animal test.

Deletion of the animal test. Changing sector specific legislation to replace any requirement for a specific animal test with the alternative takes several years and the process is usually not started until the very end of the process. Political pressure is usually needed to instigate the deletion of the animal test, often following pressure from animal protection organizations. For example, there was a delay of seven years from the point in which there was a formal method alternative to the rabbit skin irritation test (Commission of the European Communities, 2009) until the rabbit test was deleted from REACH requirements and replaced with the skin irritation methods (European Commission, 2016a). The process was not initiated until 2012, following a complaint from Cruelty Free International. To date, the rabbit test is still performed in Europe and elsewhere, and the formal test method for the rabbit test (OECD 
TG 404) still exists. The only standard regulatory animal test that has been deleted from OECD requirements is the LD5O acute toxicity test (OECD, TG 401) in 2001, which was "replaced" by other animal tests that cause slightly less suffering or equivalent suffering to fewer animals.

Regulatory acceptance is not usually required for methods that replace animals in basic research conducted in academe. Here, the route to acceptance is a less defined, unofficial, and often very slow process. The scientific community may gradually move towards alternative methods, usually through the common scientific channels of publications, conferences, and workshops. There is no body within the medical research establishment tasked with coordinating this process, although national ${ }_{3} \mathrm{R}$ centers may facilitate more rapid progress on a case-by-case basis. Regulators of animal experiments could play a role in ensuring that no animal-based projects are conducted in their region if there is an alternative; but as the line between what is and what is not an accepted alternative is less clear for basic research, they currently do not appear to do so.

In summary, the development and validation stages are primarily sciencedependent processes, which can be sped up through appropriate funding and coordination. The stages of formal test method, regulatory acceptance, and deletion of the animal tests are primarily regulation dependent and can be accelerated by political will and regulatory enforcement.

The difficulties of replacing animal tests, combined with increasing frustration with the lack of reliability of animal tests, have forced scientists, in recent years, to consider whether a paradigm shift is needed. A ground-breaking report to this effect was published by the National Academy of Sciences (NAS) in the Us in 2007. Rather than criticizing the ethics of testing on animals, the report focused on better science and set out a future vision for toxicity testing. The idea is that society should move away from using black box animal models, where tests depend on simply counting how many animals die rather than on understanding why they die. Instead, toxicology should seek to map human reactions at a more molecular and cellular level, something entirely possible in vitro. The Toxicology Testing in the 21st Century (Tox21) concept was funded on a practical level by the us government under the ToxCast project, which is screening thousands of chemicals using simple in vitro tests to help start the process of identifying toxicity pathways (Richard et al., 2016).

The NAS report has helped accelerate the concept of Adverse Outcome Pathways (AOPS) which provides the biological explanation for a single toxic event. Some toxic events, such as skin irritation and skin sensitization, may 
only have one biological explanation. For example, the AOP for skin sensitization has been described (OECD, 2012) and is made up of four steps: reaction of the substance with proteins in the skin, inflammatory responses in keratinocyte skin cells, activation of dendritic cells, and lastly the proliferation of Tcells. The first three steps now have OECD approved in chemico or in vitro tests (see Table 24.1); the fourth step is measured in the mouse LLNA.

Unfortunately, some animal tests capture many different types of toxicity, including some that are not relevant to humans. For example, repeated dose toxicity tests assess long term toxicity, which can manifest in a number of ways (e.g. cancer, liver disease, and heart disease, among others). To replace animals for these tests will require the identification of many AOPs and the development of tests for the steps within them. The thinking is that if all possible AOPs relevant to repeated dose toxicity can be mapped, then in chemico or in silico tests for only some of the key steps will need to be created. The risk is that finding all of these AOPs will take time, and animal tests will not be replaced until that happens. Nonetheless, the concept has now taken hold in Europe, and the OECD is supporting the population of a database of AOPS (OECD, n.d.).

Another development in toxicology that seeks to overcome the criticism that cell cultures are too simplistic, is the lab on a chip concept: body or organ on a chip models vary in size and complexity but essentially use engineering technology to combine small cultures of cells (e.g., liver, brain, and kidney) into a single, tiny device with fluid running between the compartments of each type of cell. The idea is to recreate some of the key organs and processes that occur within a human on a miniature scale (Marx et al., 2012). The concept is proving not as easy as it seems though, with issues regarding how to remove waste products, how to keep cells alive, and how to mimic realistic pressures within the fluidic channels. The lab on a chip and/or the AOP approach will also likely lead to the replacement of animal models for basic research (Langley et al., 2017). In a way, it should be easier to replace animal tests for drug development, since drug discovery itself is already very reductionist. New drugs are usually developed to interact with cell-based mechanisms inside the body that trigger disease. This is similar to the AOP approach, and it should be possible to model it in vitro. It is, therefore, rather incomprehensible that researchers look to a more holistic, whole animal approach to demonstrate both the efficacy and safety of a new drug, with all the added complications of lack of relevance and species differences that this brings. Encouraging researchers to justify efficacy based on human cell-based approaches and then testing the drug on a few patients in, so called futility trials (see Creanor et al., 2015, for example of a futility trial), could be one approach to speed up drug development and reduce the high number of drugs that fail in clinical trials. 
Another approach is to use technology to enable humans to be used safely in studies that would otherwise use animals in a harmful manner. Microdosing exploits the technological advances in analytical techniques to enable volunteers to be injected with novel substances at such low levels, that even potentially harmful substances do not to pose a threat (Lappin, 2015). Similarly, improvements in brain imaging technology are enabling researchers to measure human brain activity non-invasively, and at a high level of precision, so that invasive tests in monkeys will soon be considered redundant (Bailey and Taylor, 2016).

\section{Barriers to the Implementation of Alternatives and How to Overcome Them}

\subsection{The Current Scientific Paradigm}

A major stumbling block when it comes to replacing animals is the current way that hypotheses are tested in science. Figure 24.2 outlines the typical process scientists go through when testing either the safety or efficacy of a substance, or indeed any hypothesis. The process is one of testing in models of increasing complexity with growing confidence in the hypothesis, as it successfully passes each hurdle.

The most common justification for using animals is the apparent need to test a substance or idea in a "complex, whole being" before there is enough confidence that it can be tested safely in humans. The assumption behind this is that the complex, whole being will capture all possible, unforeseen ways in which the substance or idea could be harmful (or not work), avoiding harm to (or wasting time on) human volunteers. This "complexity" argument is one reason for the lack of support for in vitro based techniques, as these are seen as less complex and, therefore, inferior. The desire to capture all possible interactions appears to override the very real possibility that many of these interactions are wrong by the very nature of testing in the wrong species. This is very frustrating for those who support alternative approaches; and there appears to be a real gap between the two groups in terms of what is more important, complexity or relevance. Added to that is the fact that demonstration of

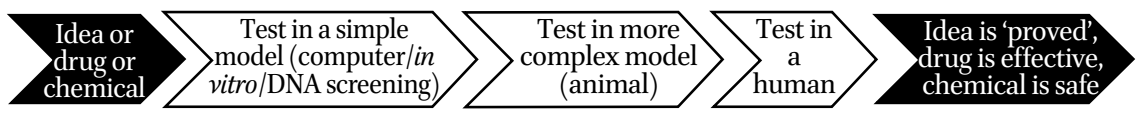

FIGURE 24.2 The standard approach to testing medical hypotheses. Confidence increases as you move from left to right. 
the predictivity of alternative methods often fails to convince those who cannot get past the fact that the alternative is simply not a live, complex animal. If an alternative method is found to be $90 \%$ predictive of effects in humans, this does not seem to provide confidence. The answer is always, "what if?" This caution has undoubtedly raised the standard by which alternative methods are measured; but some believe that the bar is, in fact, now too high and is still being unfairly applied.

The complexity versus relevance debate may be resolved by greater understanding and uptake of the AOP approach. This approach seeks to break down the complexity of biological processes on a more scientific basis. Alternative methods can be chosen that measure a distinct part of a mechanistic process that leads to an adverse effect (i.e., toxicity). Using an alternative method that is known to predict even just one step in the AOP should give confidence that it is relevant. Combining several methods that test different parts of the AOP should also help address the complexity issue. Lab on a chip methods, as well as more complex in vitro methods, such as $3 \mathrm{D}$ tissue constructs and mini-brains (see Caruso, 2017), are also another solution to increase both relevance and complexity.

\subsection{Interface with Legislation}

Scientists developing alternative methods have historically designed them to give simple answers to the question, is the substance being tested safe or toxic, yes or no? This was seen as a good first step to assist in their validation and initial adoption, even if the animal test they are designed to replace actually produces quantitative (numerical) answers on the extent of toxicity. However, failure of alternative methods to produce equivalent results to the animal tests has been one reason for the delay to their full implementation. For example, the in vitro skin irritation/corrosion methods were initially validated to give a yes/no result on whether a substance would cause skin corrosion in 1998 (ECVAM Scientific Advisory Committee, ESAC, 1998). This limited their use because chemical sector regulators actually required these methods to present the result as not irritant, irritant, or severely irritant/ corrosive. This is because the results of the animal test are used not only for risk management purposes but for classification and labelling of substances, which is governed by different legislation. It was not until 2007 that a slightly different protocol, using the same skin methods, was validated to provide this information on irritation (ESAC, 2007). Even then, it was not until 2009 (ESAC, 2009) - when a third, more rapid validation was completed because the classification and labelling requirements had changed since the start of the process - that the rabbit test was finally replaced using a combination of two methods. 
Since the issue surrounding the validation of the skin irritation methods, there is now greater recognition of the need to be aware of classification and labelling requirements, but problems still occur. For example, the in vitro skin sensitization methods were also validated to provide yes/no answers; but the regulators require three answers: no effect, weak effect, or strong sensitizing. It was for this reason that the EC and Member States recently refused to remove the mouse LLNA test from REACH requirements, as they are of the opinion that full replacement for classification and labelling is not yet possible using the in vitro methods (European Commission, 2016b).

The issue is further complicated by countries around the world that have different requirements for the classification of substances based on the same toxicity test results. The alternatives are often only validated against one scheme. For chemicals, this is often the United Nations Globally Harmonized System (UN GHS) of Classification and Labelling of Chemicals, but this is not recognized by all countries and all legislations that may have different requirements. So, two additional hurdles are getting those involved in the validation of alternative methods to appreciate the regulatory use of the method and validate it accordingly and getting countries to harmonize their regulatory requirements, irrespective of the methods used, to satisfy the requirements. Lack of international harmonization of classification and labelling requirements is one of the reasons why rabbit skin irritation tests are still being conducted in Europe for non-EU regulators, even though the alternatives are now accepted within Europe.

\subsection{Bureaucracy}

Bureaucracy plays a large part in the delay to the implementation of alternatives, in my view, particularly at the regulatory acceptance stage. Much of this bureaucracy could be avoided as illustrated below. It is, in my opinion, in part caused by inertia amongst regulators and a failure to incentivize and reward them for evaluating new methods. The process still largely relies on the goodwill of a few experts from a few countries. Industry are not specifically rewarded for developing alternatives and, indeed, run some risk if the alternative is not accepted (due to wasted development costs). Regulators also run the risk of accepting a method that could fail in the real world, potentially causing harm to humans. Hiding behind bureaucratic delays avoids having to make a decision.

There are bureaucratic delays caused by the desire to harmonize testing requirements internationally. Harmonization is seen as a good thing, as it means that, in theory, a single (animal) test conducted in a laboratory in one country will be accepted for regulatory submission of that substance in all countries that sign on the agreement. This is called Mutual Acceptance of Data (MAD). 
There have been tremendous efforts in the past 20 years to encourage the chemical and drug sectors to harmonize their requirements. As alternatives have been developed, they too have had to go through this harmonization process. In theory, this is also a good thing, because once accepted no more animal tests would be required around the world for that specific substance. However, in reality the process of negotiation takes a long time; and to speed up the process, loopholes are placed in documents that can give a false sense that harmonization has actually been achieved. A recent example is skin sensitization, where the alternative methods gained OECD acceptance relatively easily, but on the understanding that they cannot be used as standalone replacements. Therefore, there is no requirement for countries to accept these methods to replace the corresponding animal test, until perhaps another formal document is agreed on at some point in the future that shows how they can be used together.

In the EU the situation is further complicated. The EU defers to the OECD on the basis that international harmonization is preferable to $\mathrm{EU}$ acceptance (ignoring the fact that the $\mathrm{EU}$ is already a grouping of 28 countries). This causes on average two years' delay to a method that was validated in Europe. They then require that the test method, as agreed by the OECD, be published in the official EU regulations (Commission of the European Communities, 2008, Test Methods Regulation EC440/2008,) in an almost completely bureaucratic process that takes, on average, a further two to three years. For example, the first version of the reconstituted skin model was validated by ECVAM for detecting corrosive substances in 1998 (ESAC, 1998); but it was not adopted by the OECD until 2004 (OECD, TG 431). The first version of the model for skin irritation was validated in 2007 (ESAC, 2007); but it was not adopted by the OECD until 2010 (OECD TG 439). Due to political pressure at the time, the EU adopted an unusual procedure and accepted the skin methods before the OECD in 2000 for corrosion (European Parliament and the Council of the EU, 2000), and in 2009 for irritation (Commission of the European Communities, 2009). The EU has not done this since, even though similar delays have occurred for other methods. For example, the DPRA for skin sensitization was validated in 2012 (ESAC, 2012); but it was not published as OECD TG $44 \mathrm{C}$ until 2015. Over two years after its publication in the OECD, it was published in the EU Test Methods Regulation (Commission of the European Communities, 2017).

One could argue that the bureaucratic delay between validation and regulatory acceptance gives industry time to advance their knowledge of the new methods, get them into place and gain confidence in their use. In reality, companies, other than those directly involved in the development and validation of the new method, tend to remain unaware of these methods until they are 
accepted. If they do become aware of them, they tend to wait for confirmation that they will be accepted, before investing in using them. One of the reasons for the delays at both the OECD and the EU's Test Methods Regulation is the timing of the cycle for revising test guidelines. The process is annual at the OECD; if you miss the deadline for submitting methods, you lose one year. Given sufficient political will, it should be entirely possible to speed up the process by increasing the cycle of meetings and, in Europe, by accepting that as most $\mathrm{EU}$ members are also members of the OECD, there is little need for a second round of negotiation to update the Test Methods Regulation.

\subsection{Lack of Funding}

Obtaining funds to develop replacements for animal tests is still very difficult, despite a few high profile, one-off, significant projects. For example, in response to the imminent cosmetics testing bans in 2009, the EC and the cosmetics industry each contributed $€_{25}$ million towards the development of alternatives to animals for long-term toxicity testing (SEURAT-1, n.d.). Furthermore, the EC claims it has funded replacement methods in the last main scientific-funding stream, Framework Project 7 (2007-2013), to a total of $€_{180}$ million (European Commission, 2013). However, compared to overall science funding, the levels of investment are relatively low. The total Framework Project 7 budget was $€_{45.3}$ billion; as such, the Commission dedicated only $0.4 \%$ of its science budget to alternatives to animal testing.

National funding levels are even lower than central funding, perhaps reflecting a general apathy about the need to improve the humanity and reliability of scientific methods. We recently compiled a survey of EU countries and found that direct funding of alternative $(3 \mathrm{Rs})$ methods was reported to total only $€ 18.7$ million in 2013 (Taylor, 2014). Only seven countries provided this funding: Austria, Belgium, Denmark, Finland, Germany, Sweden, and the UK. Much of this budget was dedicated to support national centers for the ${ }_{3} \mathrm{Rs}$ rather than the development of new methods. Funding by the most generous country, the UK (approximately $€ 11$ million), was still only $0.04 \%$ of its national science research and development expenditure for that year.

Central and national funding of alternatives, therefore, exists but is relatively very low and $a d$ hoc. This compares poorly to the funding given to equally ambitious big picture projects. For example, former us President Obama's project to map the human brain was funded by us $\$ 100$ million (The White House, President Barak Obama, n.d.); and the human genome project by us $\$ 3.8$ billion (Human Genome Research Institute, n.d.). However, these are single projects. Replacing all animal tests, even only in the field of regulatory toxicology comprises many, many projects. Clearly, the rate of change is likely to be slow 
unless levels of funding significantly increase and are proportionate to the scale of the problem being addressed.

\subsection{Entrenchment}

Many of the remaining animal tests to be replaced, particularly for regulatory testing, have remained unchanged since they were first developed many decades ago. For example, the pyrogenicity test in rabbits (used to establish if injectable drugs are contaminated) was developed in 1912 (Hort and Penfold, 1912); the Draize skin irritation test on rabbits in 1944 (Draize et al., 1944); and the Buehler guinea pig skin sensitization test in 1965 (Buehler, 1965).

Entrenchment is common in science (Kuhn, 1962). This may seem counter intuitive when one considers that what defines science is its questioning nature. But even those who use animals in research will attest to the difficulty in getting funding for new approaches, as well as the difficulty in publishing research that uses a method that is different from the one everyone else is using. Behind closed doors, researchers will complain about journal editors even asking for their idea to be demonstrated in an animal model before they will publish it (see Cronin, 2017; discussions at the recent EC conference on alternatives). This situation is partly caused by the fact that those who are conducting research, reviewing papers, and reviewing funding applications are usually from within the same scientific peer group. New ideas that threaten the status quo can struggle to gain support; and researchers who are unhappy about their treatment are often afraid to speak up, in case it affects their university tenure or funding.

Preferentially funding scientists who want to use different methods is a system that could work to promote change. However, apart from occasional large projects, such funding is still only taken on by specialist replacement charities with small budgets. Once they are a part of a project to replace animals, however, scientists can create a support network that can help to foster change; but it is crucial that funding is dependable for this to be sustained. Another solution is finding a way to include fresh perspectives on the types of projects being funded. Including experts who are more motivated to challenge the need to test on animals in the ethical review of projects involving animals, such as individuals with expertise in alternatives or in animal protection, could have a big impact. Currently, funding and licensing bodies only tend to include token lay persons in their discussions, who can feel out of depth and overwhelmed. Making applications or, at the very least, the funding policies of granting bodies open to regular public scrutiny could also help. 


\subsection{Lack of Enforcement}

If improved funding of alternatives is the carrot, then enforcement is probably the stick. Although, most would say the carrot is the best approach for entrenched issues such as this, enforcement still has a role to play. In Europe, since 1986, it has been illegal, on paper, to conduct an animal test "if another scientifically satisfactory method of obtaining the result sought, not entailing the use of an animal, is reasonably and practicably available" (Council of the European Communities, 1986, Directive 86/6og/EEC). Unfortunately, in 2010 this was watered down, to some extent, with a stricter onus being placed on methods that are "recognized under the legislation of the Union," although the general premise remains. "Member States shall ensure that, wherever possible, a scientifically satisfactory method or testing strategy, not entailing the use of live animals, shall be used instead of a procedure" (European Parliament, 2010).

Technically the onus is on the Member State to not authorize animal tests where alternatives exist, rather than on the researcher. Our experience has shown, however, that if Member States can divest themselves of this, they will. Laboratories are granted multiple generic licenses that do not cover the specific substances being tested, which makes it impossible for the authorizing body to make decisions as to whether an alternative method is suitable. This is a particular issue with quality control tests, where the alternative can often be used for some substances and not others. Following an undercover investigation, Cruelty Free International recently demonstrated that a contract testing facility in the UK was testing substances for pyrogens on rabbits, for which the alternative bacterial endotoxin test was suitable, according to the European Pharmacopeia (see Cruelty Free International, n.d.). It was not until we challenged the UK competent authority that they began asking for substancespecific information in advance (Animals in Science Regulation Unit, 2014).

Enforcement of the use of alternatives for basic research is more complex and is currently being largely overlooked by regulators of animal experiments. Due to the myriad of ways in which animals can be used to test medical hypotheses, and the lack of formal standardized approaches, regulators tell us that they cannot really enforce the use of alternatives as they would for safety testing. Currently, in the $\mathrm{UK}$, the onus is on the researcher, rather than the regulator to demonstrate the absence of an alternative approach. The regulator, assessing a potential project that intends to use animals, is not usually an expert in the area; and it is not clear to what extent researchers are really being challenged in their statements that alternatives are not available. The solution is for regulatory bodies to simply take responsibility for upholding the law when an alternative method is available that can prevent animal experiments or at 
least partially replace them. Currently, some animal protection organizations see it as part of their role to hold regulators accountable to encourage them to do this. A better solution would be if a tougher stance was accepted internally by the regulators, perhaps as a consequence of a directive from their governments.

It is clear from Table 24.1 that prior to the EU cosmetics testing bans, there was very little regulatory approval of alternative methods. There is a clear acceleration from 2003, the date of the implementation of the first testing ban (for products). But now that Europe has a complete ban on cosmetics testing on animals, it is important that this momentum is not lost. It is possible that, with public support, new bans or deadlines could be put in place. There are already calls for bans on the testing of household products and all testing on dogs and monkeys. Using prohibitions on testing as an incentive for the development of alternatives is, however, hitting a hurdle in these areas. Animal testing for medical purposes is seen as something that cannot end until alternatives are available, and setting a timeline for science to replace animal experiments is not considered by some to be possible or even desirable. In a Nature survey of its readers (over half of whom conducted animal experiments), $63 \%$ thought ending animal experiments was a desirable but unachievable goal (Ainsworth, 2006).

The absence of viable alternatives has, however, not hindered political agreement in a number of other areas, where the ability to realize the promise relies to some extent on science and technology, such as the case of climate change. Internationally, the Kyoto Protocol was signed by 37 industrialist countries as well as Europe, in 1997, and set the goal of a $5 \%$ reduction in carbon emissions below 1990 levels by 2012. The target was met (United Nations Climate Change, n.d.). Europe has a further commitment to reduce levels by $20 \%$ by 2020 (European Commission, n.d.). Although countries have signed up to reduce their emissions, no one is suggesting that they cease manufacturing cars or turn the power off in order to do so. Instead, goals to reduce in emissions are being met by increased efficiency and innovation (see European Commission, n.d.). One can see that a reduction in animal testing could also be achieved through more efficient use of animals (e.g., not authorizing the more "blue sky" type of basic research and using less animals for any given purpose) and investment in technology. Setting a target of, for example, a reduction of $50 \%$ in national animal experiments by 2025 will enable countries to exert power over experiments 
that they feel they could perhaps do without and to prioritize for replacement those that they cannot. Targets will feed into the ethical review committees for animal experiments, who will have to make harder decisions and actually reject some applications. Targets will also seep into the mindset of scientists, who will have to think more carefully about whether they are likely to be accepted before putting forward applications for new animal experiments. There will be more political will to fund alternatives and put in place the necessary governmental and institutional schemes to fund, develop, promote, and implement alternatives.

It is important to remember that reduction in animal experimentation will not always rely on replacement. It is unfortunate that this view, however, prevails even in Directive 2010/63/EU, which states that "this Directive represents an important step towards achieving the final goal of full replacement of procedures on live animals for scientific and educational purposes as soon as it is scientifically possible to do so" (European Parliament, 2010). In the area of basic research in particular, where the majority of animals are actually used (Daneshian et al., 2015), there is much more of an element of choice in conducting an animal experiment. In a world with infinite questions about human biology, there are equally important questions that can be tackled that do not require resorting to animal experiments. Some scientists choose to use animals, but they could choose to study humans, or cells, or computer models and still contribute to the pool of medical knowledge. If we change the goal to one of improving the humanity and quality of medical knowledge, rather than replacing like for like, then, in my opinion, a significant proportion of animal research could end today.

\section{7}

\section{Conclusion}

The field of alternatives research has accelerated in the past 30 years, largely as a result of legislative pressures on specific sectors to end testing and/or use alternatives. There are now alternatives for a significant proportion of the standard "battery" of animal tests, which are typically required to test the safety of new chemicals and drugs. Unfortunately, the corresponding removal of the animal tests that these new alternatives replace is still forthcoming. There are many reasons why animal testing persists even, when there are alternatives, which have little to do with the scientific limitations of the new tests. Human limitations, including bureaucracy, political malaise, and entrenchment in the scientific establishment are as great, if not greater, barriers to the replacement of animals in testing. 
There needs to be a paradigm change in the way science approaches many of its questions. The classic approach of test your idea or substance in a simple model, such as a cell culture; and then if successful test it in a more complex mod$e l$, such as an animal, needs to change. Funding bodies and journals need to stop requiring proof of concept in animal models but in more human-relevant approaches. A more mechanistic approach is one possible way to facilitate the use of alternatives. Breaking down the question you need to answer into questions that can be tested in simpler models would facilitate a speedier uptake of alternatives. Another approach is to employ technology to overcome some of the current problems of using humans ethically or to increase the complexity of cell-based systems. Whether these two approaches will complete or complement each other remains to be seen.

What will encourage science to change its paradigm? Political will needs to be amplified and targets for a reduction of animal experiments are needed. This, in turn, will help increase levels of funding to speed up the development of new approaches and reduce regulatory malaise, so that they are implemented as soon as they appear.

\section{References}

Ainsworth, C. (2006). Scientists Share Thoughts on Animal Research: Poll Reveals Nuanced Views Among Biomedical Researchers. Nature, News [online] Available at: http://www.nature.com/news/2006/o61211/full/newso61211-9.html [Accessed 15 February 2018].

Animals in Science Regulation Unit (2014). Naming of Products and Substances in Project licenses for Batch Quality Control and Regulatory Toxicology. London, UK: Home Office.

Auplat, C. (2012). From technical innovation to innovation in management practice: The case of Episkin. In: H. Fulford, ed., Case Studies in Innovation for Researchers, Teachers, and Student, Vol. 1. London, U K: Academic Conferences and Publishing International Limited.

Bailey, J. and K. Taylor (2016). Non-human Primates in Neuroscience Research: The Case Against Its Scientific Necessity. Alternatives to Laboratory Animals, 44, pp. $43-69$.

Balls, M. (2006). International validation and barriers to the validation of alternative tests. In: R.E. Hester, and R.M Harrison, eds., Issues in Environmental Science and Technology: Alternatives to Animal Testing. London, UK: Royal Society of Chemistry. Bookchin, D. and J. Schumacher (2005). The virus and the vaccine: Contaminated vaccine, deadly cancers, and government neglect. New York: St Martin's Press. 
Buehler, E.V. (1965). Delayed Contact Hypersensitivity in The Guinea Pig. Archives of Dermatology, 91, p. 171.

Caruso, C. (2017). The Beauty of "Mini Brains": Lab-grown Bundles of Brain Cells May Be the Future of Drug Testing. Scientific American Mind, 28, p. 76.

Commission of the European Communities (2008). Council Regulation (EC) No 440/2008 of 30 May 2008 Laying Down Test Methods Pursuant to Regulation (EC) No 1907/2006 of the European Parliament and of the Council on the Registration, Evaluation, Authorisation and Restriction of CHemicals (REACH). Official Journal of the European Communities, L 142, pp. 1-739.

Commission of the European Communities (2009). Commission Regulation (EC) No $761 / 2009$ of 23 July 2009 Amending, for the Purpose of Its Adaptation to Technical Progress, Regulation (EC) No 440/2008 Laying Down Test Methods Pursuant to Regulation (EC) No 1907/2006 of the European Parliament and of the Council on the Registration, Evaluation, Authorisation and Restriction of CHemicals (REACH). Method B.46 of the Annex to 440/2008/EC. Official Journal of the European Communities, L 220, pp. 1-94.

Commission of the European Communities (2017). Commission Regulation (EC) No 761/2009 of 14 February 2017 Amending, for the Purpose of Its Adaptation to Technical Progress, Regulation (EC) No 440/2008 Laying Down Test Methods Pursuant to Regulation (EC) No 1907/2006 of the European Parliament and of the Council on the Registration, Evaluation, Authorisation and Restriction of Chemicals (REACH): Method B.59 of the Annex to 440/2008/EC. Official Journal of the European Communities, L 112, pp. 1-402.

Council of the European Communities (1986). Council Directive 86/6og/EEC of 24 November 1986 on the Approximation of Laws, Regulations and Administrative Provisions of the Member States Regarding the Protection of Animals Used for Experimental and Other Scientific Purposes. Official Journal of the European Communities, L 358, pp. 1-28.

Creanor, S., J. Vickery, V. Eyre, J. Zajicek, S. Ball, J. Elm and C. Carroll (2015). Two-arm Randomised Futility Trials: PD-stat, a Futility Trial of a Potential Neuroprotective Treatment in People with Parkinson's Disease. Trials, 16(2), p. 236.

Cronin, M. (ed.) (2017). Non-Animal Approaches. The Way Forward. Report on a European Commission Scientific Conference, Brussels, Belgium, 6-7 December 2016. [online] Available at: http://ec.europa.eu/environment/chemicals/lab_animals/3r/ pdf/scientific_conference/non_animal_approaches_conference_report.pdf [Accessed 15 February 2018].

Cruelty Free International (n.d.). Animal Experiments at Wickham Laboratories. Exposed: Appalling Suffering at a UK Animal Testing Laboratory. [online] Available at: https://www.crueltyfreeinternational.org/what-we-do/investigations/animal -experiments-wickham-laboratories [Accessed ${ }_{15}$ February 2018]. 
Daneshian, M., F. Busquet, T. Hartung and M. Leist (2015). Animal Use for Science in Europe. Alternatives to Animal Experimentation, 32(4), pp. 261-274.

Draize, J.H., G. Woodard and H.O. Clavery (1944). Methods for the Study of Irritation and Toxicity of Substances Applied Topically to the Skin and Mucous Membranes. Journal of Pharmacology and Experimental Therapeutics, 82, pp. 377-390.

ECVAM Scientific Advisory Committee (ESAC) (1998). ESAC Statement on Scientific Validity of EpiSkin (SkinEthic) for Corrosivity Testing. Ispra, Italy.

ESAC (2007). ESAC Statement on Scientific Validity of EpiSkin and EpiDerm for Skin Irritation Testing. Ispra, Italy.

ESAC (2009). ESAC Statement on the Performance under UN GHS of Three In Vitro Assays for Skin Irritation Testing and the Adaptation of the Reference Chemicals and Defined Accuracy Values of the ECVAM Skin Irritation Performance Standards. Ispra, Italy.

ESAC (2012). EURL ECVAM Recommendation on the Direct Peptide Reactivity Assay (DPRA) for Skin Sensitisation Testing. Ispra, Italy: European Commission, Joint Research Centre, Institute for Health and Consumer Protection (IHC), Nov 2013 EUR 26383 EN.

European Commission (n.d.). 2020 Climate \& Energy Package. [online] Available at: https://ec.europa.eu/clima/policies/strategies/2020_en [Accessed 15 February 2018].

European Commission (2013). Report from the Commission to the European Parliament, the Council, the European Economic, and Social Committee, and the Committee of the Regions in accordance with Article 117(4) of REACH and Article 46(2) of CLP, and a Review of Certain Elements of REACH in line with Articles 75(2), 138(2), 138(3) and 138(6) of REACH. Brussels, Belgium: 5.2.2013 COM(2013) 49 final.

European Commission (2016a). Commission Regulation (EU) 2016/863 of 31 May 2016 Amending Annexes VII and VIII to Regulation (EC) No 1907/2006 of the European Parliament and of the Council on the Registration, Evaluation, Authorisation and Restriction of CHemicals (REACH) as Regards Skin Corrosion/Irritation, Serious Eye Damage/Eye Irritation and Acute Toxicity. Official Journal of the European Communities, L 144, pp. 27-31.

European Commission (2016b). Commission Regulation (EU) 2016/1688 of 20 September 2016 Amending Annex VII to Regulation (EC) No 1907/2006 of the European Parliament and of the Council on the Registration, Evaluation, Authorisation and Restriction of CHemicals (REACH) as Regards Skin Sensitisation. OfficialJournal of the European Communities, L 255, pp. 14-16.

European Commission (2017). Ban on Animal Testing. [online] Available at: https:// ec.europa.eu/growth/sectors/cosmetics/animal-testing_en [Accessed 12 January 2017]. 
European Parliament (2010). Directive 2010/63/EU of the European Parliament and of the Council of 22 September 2010 on the Protection of Animals Used for Scientific Purposes. OfficialJournal of the European Communities, L276,p. 33-79. [online] Available at: http://eur-lex.europa.eu/legal-content/EN/TXT/?uri=CELEX:32010Loo63 [Accessed 15 February 2018].

European Parliament and the Council of the European Union (2000). EU Directive 2000/33/EU for the 21st Amendment of Annex V of the EU Directive 86/906/EEC for Classification and Labelling of Hazardous Chemicals: Test Guideline B-4o Skin Corrosivity In Vitro Method and Test Guideline B-41 Phototoxicity In Vitro 3T3 NRU Phototoxicity Test. Official Journal of the European Communities, L136, 90-107.

European Parliament and the Council of the European Union (2006). REACH Regulation (EC) No 1907/2006 Regulation Concerning the Registration, Evaluation, Authorisation and Restriction of CHemicals (REACH), Establishing a European Chemicals Agency (ECHA). Official Journal of the European Communities, L396, pp. $1-849$.

Friedman, M.H. (1939). The Assay of Gonadotropic Extracts in the Post-partum Rabbit. Journal of Endocrinology 24 (5), pp. 617-625.

Hartung, T. (2007). Food for Thought...on Validation. Alternatives to Animal Experimentation, 24, pp. 67-73.F.

Hort, E.C. and W.J. Penfold (1912). A Critical Study of Experimental Fever. Proceedings of the Royal Society B, 85(578), pp. 174-186.

Human Genome Research Institute (n.d.). Research Funding. [online] Available at: https://www.genome.gov/researchfunding/ [Accessed 15 February 2018].

Joint Research Centre (2006). Briefing Note on Number of Animals Expected to Be Used under REACH: Summary of Re-assessment Performed by the JRC. Ispra, Italy: European Commission, Directorate General Joint Research Centre, Institute for Health and Consumer Protection.

Kuhn, T. (1962). The structure of scientific revolutions. Chicago, IL: University of Chicago Press.

Langley, G.R., I.M. Adcock, F. Busquet, K.M. Crofton, E. Csernok, C. Giese, T. Heinonen, K. Herrmann, M. Hofmann-Apitius, B. Landesmann, L.J. Marshall, E. McIvor, A.R. Muotri, F. Noor, K. Schutte, T. Seidle, A. van de Stolpe, H. Van Esch, C. Willett and G. Woszczek (2017). Towards a 21st-century Roadmap for Biomedical Research and Drug Discovery: Consensus Report and Recommendations. Drug Discovery Today, 22(2), pp. 327-339.

Langley, G.R, C.P. Austin, A.K. Balapure, L.S. Birnbaum, J.R. Bucher, J. Fentem, S.C. Fitzpatrick, J.R. Fowle, R.J. Kavlock, H. Kitano and B.A. Lidbury (2015). Lessons from Toxicology: Developing a 21st-Century Paradigm for Medical Research. Environmental Health Perspectives, 123(11), pp. A268-A272. 
Lappin, G. (2015). The Expanding Utility of Microdosing. Clinical Pharmacology and Drug Development, 4(6), pp. 401-406.

Liebsch, M., B. Grune, A. Seiler, D. Butzke, M. Oelgeschläger, R. Pirow, S. Adler, C. Riebeling and A. Luch (2011). Alternatives To Animal Testing: Current Status and Future Perspectives. Archives in Toxicology, 85(8), pp. 841-858.

Marx, U., H. Walles, S. Hoffmann, G. Lindner, R. Horland, F. Sonntag, U. Klotzbach, D. Sakharov, A. Tonevitsky and R. Lauster (2012). "Human-on-a-Chip” Developments: A Translational Cutting-edge Alternative to Systemic Safety Assessment and Efficiency Evaluation of Substances in Laboratory Animals and Man?. Alternatives to Laboratory Animals, 40(5), pp. 235-257.

National Academy of Sciences (2007). Toxicity testing in the Twenty-first Century: A vision and a strategy. Washington DC: National Academies Press.

Organisation for Economic Co-operation and Development (OECD) (2012). The Adverse Outcome Pathway for Skin Sensitisation Initiated by Covalent Binding to Proteins. Part 1: Scientific Evidence. OECD Series on Testing and Assessment, 168, ENV/ JM/MONO(2012)10/PART1.

OECD (n.d.) AOP Knowledge Base. Search portal. [online] Available at: https://aopkb .oecd.org/search.ashx [Accessed 15 February 2018].

OECD (2014a). New Guidance Document on an Integrated Approach on Testing and Assessment (IATA) for Skin Corrosion and Irritation. OECD Series on Testing and Assessment, 203, ENV/JM/MONO(2014)19.

OECD (2014b). Guidance on Grouping of Chemicals, 2nd ed. OECD Series on Testing and Assessment, 194, ENV/JM/MONO(2015)18.

OECD (2015). Guidance Document on the In Vitro Syrian Hamster Embryo (SHE) Cell Transformation Assay. OECD Series on Testing and Assessment, 214, $\mathrm{ENV} / \mathrm{JM} / \mathrm{MONO}(2015) 18$.

OECD (2016). Guidance Document on the In Vitro Bhas 42 Cell Transformation Assay. OECD Series on Testing and Assessment, 231, ENV/JM/MONO(2016)1.

Richard, A.M., R.S. Judson, K.A. Houck, C.M. Grulke, P. Volarath, I. Thillainadarajah, C. Yang, J. Rathman, M.T. Martin, J.F. Wambaugh and T.B. Knudsen (2016). The ToxCast Chemical Landscape: Paving the Road to 21st Century Toxicology. Chemical Research in Toxicology, 29(8), pp. 1225-1251.

SEURAT-1 (n.d.) Towards Replacement of In Vivo Repeated Dose Systematic Toxicity Testing. [online] Available at: http://www.seurat-1.eu [Accessed 15 February 2018].

Taylor, K., N. Gordon, G. Langley, and W. Higgins (2008). Estimates for Worldwide Laboratory Animal Use in 2005. Alternatives to Laboratory Animals, 36, pp. 327-342.

Taylor, K. (2014). EU Member State Government Contribution to Alternative Methods. Alternatives to Animal Experimentation, 31, pp. 215-222.

The White House President Barak Obama (n.d.) The Brain Initiative. [online] Available at:https://obamawhitehouse.archives.gov/node/300741 [Accessed 15 February 2018]. 
Underhill, L.A., R. Dabbah, L.T. Grady and C.T. Rhodes (1994). Alternatives to Animal Testing in the USP-NF: Present and Future. Drug Development and Industrial Pharmacy, 20, pp. 165-216.

United Nations Climate Change (n.d.). Kyoto Protocol Introduction. [online] Available at: http://unfccc.int/kyoto_protocol/items/2830.php [Accessed 15 February 2018].

World Health Organization (WHO) (2007). Guidelines for Plague Reduction Neutralisation Testing of Human Antibodies to Dengue Viruses. WHO/IVB/07.07. [online] Available at: http://apps.who.int/iris/bitstream/10665/69687/1/who_ivb_07.07_eng .pdf [Accessed 15 February 2018]. 